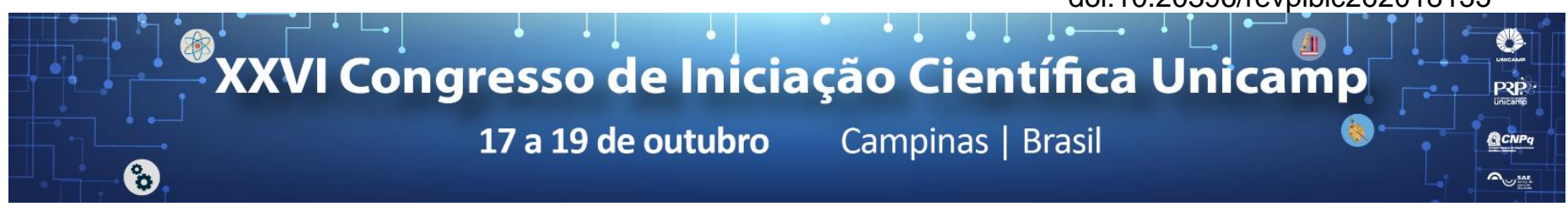

\title{
As Estratégias Relacionadas à Lição de Casa de Estudantes do Ensino Fundamental
}

\author{
Ana Paula Bonfim Hirai*, Evely Boruchovitch
}

\begin{abstract}
Resumo
Para se obter bons resultados, tanto na hora de aprender quanto no desempenho escolar, é essencial que os alunos realizem a lição de casa de uma maneira eficiente. Considerando a relevância de se conhecer melhor como alunos da Educação Básica a realizam, o presente projeto de pesquisa deu continuidade a projetos da orientadora (CNPq). A amostra foi composta por 80 alunos de ambos os sexos, do $3^{\circ}, 5^{\circ}, 7^{\circ}$ e $9^{\circ}$ ano de uma escola particular do município de Piracicaba/SP. Os dados foram coletados por meio de uma escala Likert e o desempenho escolar foi aferido com base nos conceitos de Português e Matemática dos alunos. Os resultados obtidos sugerem que a lição de casa pode ser uma ferramenta importante para a aprendizagem dos alunos, visto que os auxilia a desenvolverem melhores hábitos na hora de aprender e consequentemente a terem um melhor desempenho escolar.
\end{abstract}

\section{Palavras-chave:}

Tarefa de casa; Educação Básica, Estratégias de aprendizagem.

\section{Introdução}

A aprendizagem atualmente exige que o aluno seja capaz de se autorregular e se responsabilizar pelo seu próprio processo de aprendizagem. Assim, a realização da lição de casa é considerada como uma das estratégias que auxilia o aluno a obter uma aprendizagem bem-sucedida. Neste sentido, os objetivos do estudo são: caracterizar as estratégias relacionadas a realização da lição de casa de estudantes de $3^{\circ}, 5^{\circ}, 7^{\circ}$ e $9^{\circ}$ ano do Ensino Fundamental de escolas públicas e/ou particulares de Piracicaba; Explorar relações entre as estratégias relatadas pelos estudantes para a realização da lição de casa e o seu desempenho escolar em português e matemática; Verificar se existem diferenças nas estratégias relacionadas à realização da lição de casa e a idade, o sexo e o ano escolar dos participantes.

\section{Resultados e Discussão}

De acordo com os resultados obtidos, notou-se que entre os dois fatores apresentados na escala, as ações favoráveis à aprendizagem (Fator 2) predominaram entre os participantes mais novos, em relação as ações desfavoráveis à aprendizagem (Fator 1). Analisando também as médias dos alunos com relação aos dois fatores, percebe-se que houve uma leve diminuição no sétimo e no nono ano, em relação ao terceiro e quinto ano, tanto nos fatores, quanto na escala total. Portanto, podese perceber que os alunos mais novos são os que mais possuem hábitos e estratégias de aprendizagem na hora de realizar a lição de casa, quando comparados aos participantes mais velhos, deste estudo. Aventa-se como hipótese para o declínio observado o fato de que os estudantes avaliados, possam não ter piores hábitos, mais sim que, possam estar mais desmotivados para usálos, visto que na literatura consultada, a variável motivação para aprender possui um declínio com o avançar da idade e do ano escolar. No que diz respeito ao desempenho escolar, a maioria dos alunos está acima da média tanto em Português quanto em Matemática. Ao relacionar o desempenho escolar com os resultados dos fatores, observou-se que os alunos que apresentaram bons hábitos e estratégias para realizar a lição de casa, tendem a ter melhores rendimentos escolares.
Tabela 1. Resultados das variáveis em relação aos anos escolares

\begin{tabular}{c|c|c|c|c}
$\begin{array}{c}\text { Ano } \\
\text { Escolar }\end{array}$ & & Fator 1 & Fator 2 & Escala Total \\
\hline $\mathbf{3}^{\circ}$ ano & Média & 36.45 & 35.80 & 72.25 \\
& Máximo & 44 & 42 & 81 \\
& Mínimo & 29 & 27 & 64 \\
\hline $\mathbf{5}^{\circ}$ ano & Média & 36.57 & 37.67 & 74.23 \\
& Máximo & 43 & 44 & 87 \\
& Mínimo & 26 & 28 & 54 \\
\hline $\mathbf{7}^{\circ}$ ano & Média & 32.94 & 34.06 & 67.00 \\
& Máximo & 39 & 41 & 80 \\
& Mínimo & 23 & 26 & 53 \\
\hline $\mathbf{9}^{\circ}$ ano & Média & 34.08 & 32.92 & 67.00 \\
& Máximo & 39 & 39 & 76 \\
& Mínimo & 27 & 26 & 55
\end{tabular}

\section{Conclusões}

Observa-se que os alunos que desenvolvem melhores hábitos e estratégias de aprendizagem na hora de realizar a lição de casa, tendem a obter melhores rendimentos escolares, visto que estão mais motivados a se dedicar aos estudos. Com base nos estudos da área e os resultados obtidos, conclui-se que a lição de casa é uma ferramenta vantajosa para a aprendizagem. Se for bem aplicada pode trazer benefícios como o desenvolvimento da autonomia do estudante.

\section{Agradecimentos}

Agradecimentos a CNPq, a minha orientadora Prof ${ }^{-}$Dr $^{\text {a }}$ Evely Boruchovitch, ao grupo GEPESP, a escola e aos alunos que participaram dessa pesquisa.

Sacco, S. G. (2012). Um estudo sobre hábitos e estratégias de aprendizagem na realização da lição de casa de alunos do ensino fundamental. Dissertação de Mestrado, Universidade Estadual de Campinas, Campinas, SP, Brasil.

Suehiro A.C.B., \& Boruchovitch, E. (2016). Hábitos e estratégias para a realização da lição de casa e variáveis demográficas em estudantes do Ensino Fundamental II, Psico, 47(2), 134-141. 